\title{
Human Development of Human Capital as Per Reforms in Central Asia
}

\author{
Shirinov Anvar Qanoatovich \\ Senior Lecturer of Bukhara State University, Bukhara, Uzbekistan.Email: anvarsh@yahoo.com
}

DOI: http://doi.org/10.38177/AJBSR.2021.3309

Copyright: () 2021 Shirinov Anvar Qanoatovich. This is an open access article distributed under the terms of the Creative Commons Attribution License, which permits unrestricted use, distribution, and reproduction in any medium, provided the original author and source are credited.

\section{ABSTRACT}

In this paper, a comprehensive multi-objective model has been proposed to optimize a supply chain when new product launches and risks emerge. In doing so, primarily, a set of risks and needed mitigation strategies are identified; secondly, the essential criteria of new product development (NPD) are introduced. These criteria are then weighted by the analytic hierarchy process (AHP) approach. Based on the calculated weights, manufacturers, which are the model's second echelon are being ranked by the fuzzy-TOPSIS method. Since the model is of non-deterministic polynomial-time hardness (np-hard), due to its complexity, two different meta-heuristic algorithms-multi-objective particle swarm optimization (MOPSO) and non-dominated sorting genetic algorithm II (NSGA-II)- are conducted. Finally, the outputs of these algorithms are compared from the indices of quality, dispersion, and uniformity. The results illustrate that the production cost is of the highest rating among the most critical NPD criteria. The performance comparison of both aforementioned meta-heuristic algorithms reveals that MOPSO has the higher capability to explore the feasible region and solve the problem than NSGA-II. Whereas, from the aspect of run-time efficiency, NSGA-II has a faster execution time than MOPSO.

Keywords: Supply chain, Risk, NPD, MOPSO, NSGA-II.

\section{Introduction}

After the achievement of the independence, rapid socio-economic changes are indicating the path of development of countries in Central Asia is following. On June 23, 2020 Republic of Uzbekistan has set up plan of reaching the Top- 50 rankings in all spheres, including social, cultural, economic and political till 2030. The upward social mobility is also a serious issue in Central Asia. The roles of international financial institutions are expanded.

Nobel Prize winner Arthur Lewis in 1955 defined the goal of growth as "the expansion of human being choice". The same description was agreed in the first Human Development Report, published in 1990. The dissimilarity was that Lewis just associated the concept of wider choice with greater profits and more believed that economic growth would unavoidably lead to human development. UNICEF (Andrea Giovanni Kornera, Frances Stewart, Richard Jolie) responded to the ongoing policy of structural restructuring.

The document "Adjustment with a Human Face" was published, in which the authors of the report, without refuting the significance of structural economic transformations, called on the IMF and the World Bank to disburse more concentration to the problems of scarcity and improving human being living environment.

The primary standard was that community features should not simply be "additional" to the package of structural alteration strategies as its only transform. As an alternative, they should be included in a new comprehensive development mechanism designed for the long expression and focused on human requirements.

\section{Discussion}

Human Development Index is a premeditated arithmetical sign that receives into description not only the amount of expenditure in material goods, but also the chances for human development provided by health and education systems. The calculation of the superiority of living by means of the human development indices is based on a least 
amount set of basic indicators. Each of the basic signs quantitatively stands for one of the major directions of human growth: longevity, education and the actual standard of living.

In Central Asia Kazakhstan, Kyrgyzstan, Tajikistan, Turkmenistan, Uzbekistan are doing their best to improve their performances. Education is considered as the aptitude to acquire and gather knowledge, to communicate, to exchange information. The characteristics of education are the literacy of the adult population and the completeness of education coverage. Literacy refers to a person's aptitude to read, comprehend and write a short, plain text concerning his/ her daily life. The literacy rate of the adult population - the proportion of literates aged 15 years and older - serves as the most important basic indicator of this direction of human development. The literacy rate refers to the real population and is an indicator of the state of education, largely dependent on literacy during the previous 10-20 years. Taking into account the trends of increasing the educational level and the need for a more adequate reflection of the differences between industrial countries, education began to be measured by a mixture of two basic indicators: the literacy rate of the adult population and the cumulative proportion of students. The latter indicator is calculated as the ratio of the total number of students (enrolled) at all levels of education (primary, secondary special, higher, post-university, in-service), regardless of their age, to the total population aged 6 to 24 years.

The normal of living characterizes admission to material resources necessary for a decent existence, together with "upholding a healthy lifestyle, ensuring territorial and social mobility, in order to exchange and participation in society". The standard of income, unlike longevity and education, only opens up the opportunities available to a being, but does not decide their use. Choosing a standard indicator that adequately reflects this direction of human development is a serious problem. An ideal indicator of the standard of living would have to take into account numerous factors: personal income; income distribution among the strata of society; previously accumulated property; access to land resources and loans; communications development and mechanism of access to public consumption funds (healthcare, education, transport, utilities, etc.), individual lifestyle; family size and structure; benefits produced in the household; natural-climatic and ecological conditions in the place of residence, etc.

The Human Development Index is an intended arithmetical pointer that takes into description not only the volume of consumption of material merchandise, but also the opportunities for human development provided by health and education systems. The appraisal of the excellence of life using the human development index is based on a minimum set of basic indicators. Both of the basic markers quantitatively represent one of the main directions of human advancement: longevity, education and the actual standard of living.

The normal of livelihood exemplifies admission to material resources necessary for a decent existence, counting enjoying a strong lifestyle, ensuring protective and communal mobility, information exchange plus participation in society. The standard of living, unlike longevity and education, only opens up the opportunities available to a person, but does not determine their use. In other words, it is a tool that expands the possibility of choice, but not the choice itself. The standard of livelihood is an indirect pointer of opportunities. The choice of a basic indicator that adequately reflects this direction of human development is a serious problem. An ideal indicator of the standard of living would have to take into account numerous factors: personal income; income distribution among the strata of society; previously accumulated property; access to land resources and loans; infrastructure development and 
mechanism of access to public consumption funds (healthcare, education, transport, utilities, etc.), individual lifestyle; family size and structure; benefits produced in the household; natural-climatic and ecological conditions in the place of residence, etc.

\section{Aspects of human development}

Economic, Social, Political, Environmental, Cultural: The notion of human expansion contains four major essentials. The people should be able to increase the productivity of their life activities by fully participating in the process of generating revenue. Consequently, profitable growth is one of the components of individual potential. Each and every one populace should initially have equal opportunities in economic life, and therefore all obstacles preventing the provision of such opportunities should be eliminated. The development should be carried out in the interests of general public and from end to end their possession of efforts. The people should completely participate in the decision-making procedures that determine their lives. They are born with convinced possible abilities. The commission of human development is to create a background in which everyone can develop their abilities, and the possibilities of this development is supposed to be more and more expanded. Thus, increasing opportunities increases people's productivity, so that citizens can be efficient managers of economic growth. In turn, economic growth should be accompanied by an equal distribution of its results, which should be accessible to both present and future age groups. Finally, all populace should be authorized to partake in the executive process that affects their livelihoods.

The term "sustainable development" has been widely used since 1987, when the report of the UN World Commission on Environment and Development "Our Common Future", known as the report of G. H. Brundtland, who headed its work, was published .These concerns were behind the establishment in 1983 of the World Commission on Environment and Development by the UN General Assembly.

The number of people facing food shortages has increased by 132 million due to the COVID-19 pandemic. This is stated in a new statement by the Food and Agriculture Organization of the United Nations (FAO). The information notes that food shortages, malnutrition and hunger affect people in all countries of the world. At the same time, the number of people facing food shortages has increased by 132 million due to the COVID-19 pandemic.

According to the report, about $14 \%$ of the food produced in the world is lost at various stages: from harvesting to the receipt of finished products in retail. Another $17 \%$ of food products deteriorate or end up in the trash in consumer homes, factories, shops or public catering places.

"There are food supply disruptions, hunger and malnutrition in every country in the world. No country has been left out of these problems. 811 million people suffer from hunger, 2 billion suffer from a deficiency of micronutrients vitamins and minerals, and millions of children suffer from stunting and exhaustion, deadly forms of malnutrition." The World Bank predicts that Tajikistan's real GDP growth will be at $6.0 \%$ in 2021 and will be moderate in the medium term.

However, such a forecast for GDP growth assumes vaccination coverage of up to 50\% of the population by the end of 2022 for low- and middle-income countries, a global weakening of anti-pandemic measures and continued 
growth in economic activity, led by China and the United States. The report says that after the economic downturn in 2020, in the first half of 2021, Tajikistan's real GDP growth was $8.7 \%$ year-on-year. After the outbreak of COVID-19, the socio-economic well-being of the population deteriorated sharply, and by the end of 2020, the country remained far from full recovery. The successful economic recovery was mainly supported by the continued sharp increase in exports of precious metals, as well as the growth of private investment and consumption.

"Improvements in the global economy will contribute to the development of international trade and open up opportunities for migrants to travel and work abroad," World Bank analysts predict. In addition, the growth of remittances and foreign investment is projected, which reflects the improvement of growth prospects in Russia and China. "The recovery of the world market, according to forecasts, will cause an increase in exports of metals and minerals from Tajikistan," the World Bank report says. The recovery of China will lead to an increase in the volume of foreign investment, primarily in the mining industry of the republic. The authors of the publication emphasize that two-thirds of the direct foreign capital received this year in the republic falls on the mining industry, followed by transport and construction by a large margin (6-7\%). In the first half of this year, foreign direct investment increased by $43.7 \%$ to $\$ 118$ million. In general, in 2007-2020, over $\$ 10.3$ billion was attracted to the economy of Tajikistan from 65 countries of the world, about $30 \%$ of which accounted for China. This is followed by Russia ( $\$ 1.6$ billion), the United States ( $\$ 703$ million), the United Kingdom ( $\$ 694$ million), Kazakhstan ( $\$ 577$ million). Chinese investments are observed in almost all sectors of the economy of Tajikistan, priority is given to exploration and mining, communications, construction, financial services, electric power, infrastructure, chemical and textile industries, as well as agriculture and processing of agricultural products.

\section{Conclusion}

The greatest pressure on the state budget of Tajikistan is likely to be exerted by the costs associated with the coronavirus and infrastructure development projects, especially in the energy and transport sectors. It is reported that new waves of the pandemic will require subsequent budget expenditures to support the health system and vulnerable groups of the population. Recall that the total revenues of the state budget of the republic in 2021 are projected at 27.6 billion somoni, which is $29.8 \%$ of GDP. Worldwide, only 15 African countries reached the $10 \%$ target of vaccination against COVID-19 which means that some 40 countries of the region are lagging behind.

\section{Declarations}

\section{Source of Funding}

This research did not receive any specific grant from funding agencies in the public, commercial, or not-for-profit sectors.

\section{Competing Interests Statement}

The author declares no competing financial, professional and personal interests.

\section{Consent for publication}

Author declares that he/she consented for the publication of this research work. 


\section{Ethical Approval}

Not Applicable.

Availability of data and material

Author is willing to share data and material according to the relevant needs.

\section{References}

[1] Reflections - Lessons from Evaluations: Learning from Past Crises for Recovering from COVID-19, UNDP Independent Evaluation 02.2021, p.146.

[2] Rob D. Van Den Berg, Indran Naidoo Susan D. Tamondong, Evaluation for Agenda 2030, Providing evidence on progress and sustainability, p.424.

[3] Turdiyev B., The criterion of human indicators in development and renewals in Uzbekistan, Центрнаучныхпубликаций (buxdu. uz), 2021, T.5, №.5.

[4] Turdiyev B., Gender equality in Uzbekistan: reform and strategy, Центрнаучныхпубликаций (buxdu. uz), 2021, T.6, №.6.

[5] Shirinov A. Q., Earth overshoot day and the case of central Asian countries (Human development vs. running out of resources), Science and Education, 2021, T.2, №.2.

[6] Shirinov A. Q., The fulfillment of the commitments of sustainable development goals in the 21 st century, Academic research in educational sciences, 2021, T.2, №.6, C.1144-1153. 